\title{
BIOPHYSICAL STUDIES OF THE BONE TISSUE IN OSTEOGENESIS IMPERFECTA*
}

\author{
B. Engfeldt, A. Exgström and R. Zetterström, Stockholm, Swedex
}

From the Department of Pathology and the Department of Physical Cell Research, Karolinska Institutet, and the Paediatric Clinic, Karolinska Sjukhuset, Stockholm

Osteogenesis imperfecta is a rare hereditary or sporadically occurring disease, primarily affecting bone but sometimes also involving other mesenchymal tissues. The bones are abnormally fragile, and multiple spontaneous fractures of long bones often occur. The normal compact corticalis is absent and a loosely arranged immature spongy bone is formed. The disease may develop in utero and can sometimes be recognised immediately after birth (osteogenesis imperfecta congenita), or become clinically apparent in childhood or adolescence (osteogenesis tarda).

The etiology is unknown. The osteoblasts seem to be retarded in their function because of lack of differentiation: they are not capable of forming normal compact bone (Wilton 1932). Several investigations have been carried out to determine whether there is an abnormality in the metabolism of calcification. The blood chemistry, however, seems to be within normal limits at all ages (Albright and Reifenstein 1948).

In order to obtain further information about the disease we have examined bone specimens from four cases by biophysical methods. The distribution and amount of bone salts in different structures have been studied with microradiography. The nature and the orientation of the mineral salts have been studied with $x$-ray diffraction. The distribution and orientation of collagen has been studied in decalcified sections with polarised light. Conventional morphological methods have also been used.

\section{MATERIAL}

Case 1-Boy, eight years of age. The disease was discovered at the age of two years. A biopsy specimen was taken from the shaft of the tibia.

Case 2-Girl, three years of age at death. The disease was diagnosed immediately after birth. The case history and morphological necropsy findings were described in detail by Wilton (1932). Specimens from different bones have been investigated.

Case 3-Boy, five months of age at death. Osteogenesis imperfecta was diagnosed immediately after birth. Necropsy specimens taken from different bones.

Case 4-Girl, seven years of age at death. Birth weight $2 \cdot 3$ kilograms. No malformation known in the family. A mesenchymal disease of the osteogenesis imperfecta type was diagnosed immediately after birth. Radiographs at the age of six weeks revealed shortening and clumsy broadening of the femur, tibia and humerus, and, at several points, cyst-like thinning of the bone with several fractures (Fig. 1). The skull was rather large, but a slight suspicion that the girl was hydrocephalic was dispelled by radiography in 1948 and 1949 . The girl suffered several fractures of the tibia and femur from very slight violence. She developed severe deformities of the femur and tibia with antero-lateral curvatures. When she was seven years old it was decided to correct the deformities of the lower limbs by osteotomies on both femora. Radiographs of the long bones now revealed normal structure of the bone (Fig. 2). The girl died during the osteotomy and an additional cause of death might have been a

"This is the fourth of a series of papers entitled "Biophysical studies on bone tissue." The three earlier papers were by Engfeldt, Engström, Helander, Wilton and Zetterström (1952); Engfeldt (1953); and Engfeldt, Engström and Zetterström (1954). 
pronounced platybasia that had developed during the course of the disease. Apart from this finding the necropsy revealed a small girl for her age (height 83 centimetres, weight 17 kilograms) with a short neck and trunk. The sclerae were blue. The internal organs did not show any thing of special interest. The lower extremities were rotated outwards. The femora were abnormally short, with pronounced lateral curvature. The tibiae showed anterior curvature. The compact bone was fragile and in the diaphysis of the femora the marrow cavities were partly occluded. A slight thoracic rosary was also observed. Sipecimens from different internal organs and from bone tissue from the femur, tibia, rib and skull were investigated.

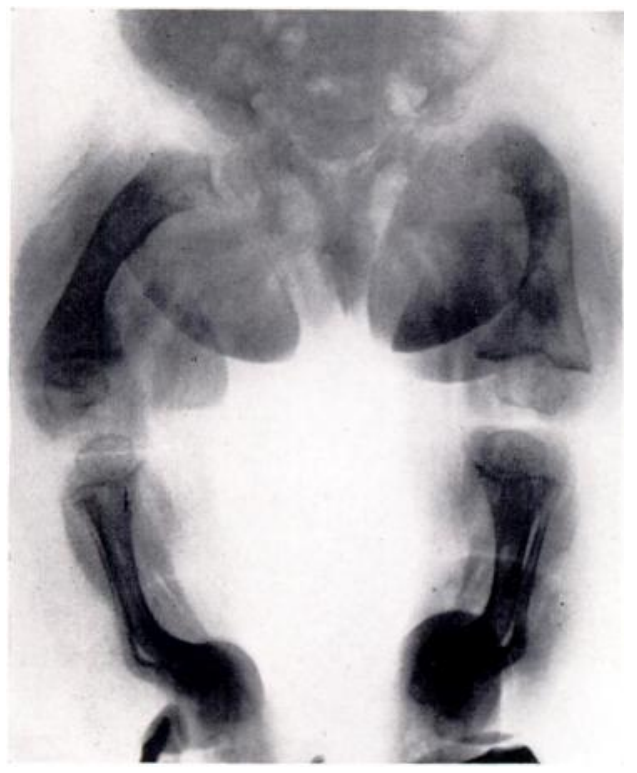

FIG. 1

(ase 4-Radlographs of lower limbs. Figure 1 At the age of thirteen months. Figure 2-. It the age of seven years. There is marked deformity of the long bones, with reduced calcification especially in the spongy part of the bone. The metaphyses are grossly intact.

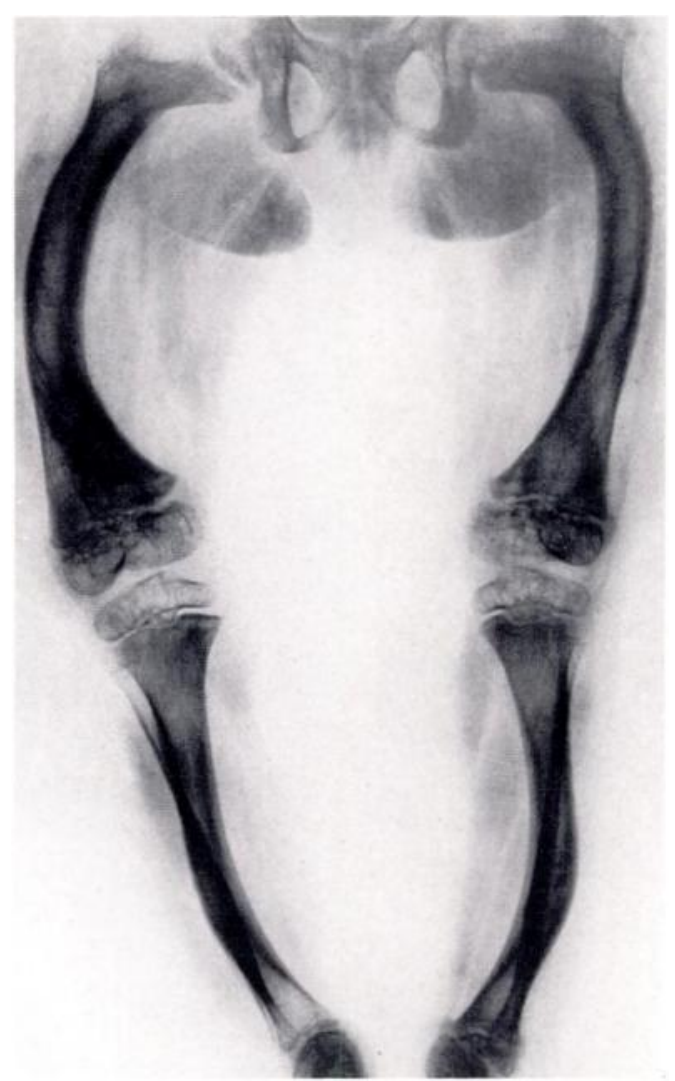

FIG. 2

METHODS. General technique - Since the bones were very fragile some of the bone specimens were embedded in methylmethacrylate before further treatment. Transverse and longitudinal sections were ground on glass plates to a thickness of $6(1)-8(1) \mu$. Decalcification of the sections was done in 5 per cent formic acid.

Microradiography-The technique was essentially the same as that described by Engström and Wegstedt (1951). A Machlett AE(; 50 tube with 1 millimetre Be-window served as the source of radiation. The tube was run at 8 kilovolts, giving $\mathrm{x}$-ray's with a short wavelength limit of $1 \cdot 5 \mathrm{~A}$., and a highest intensity at about $3 \mathrm{~A}$.-- - that is, where calcium has its greatest absorption. For large specimens, microradlographs were registered with a North American Philips diffraction unit run at 35 kilovolts and with a focus-to-emulsion distance of 25 centimetres. The microradiographs were taken on Lippman emulsion or Eastman liodak spectroscopic plate 649. The resolving power of these emulsions is about 1000 lines per millimetre. The microradiographs were enlarged by photomicrography with Kodak 0250 plates.

VOL. $36 \mathrm{~B}$, No. 4, NOYEMBER 1954 
Polarised light-The ground decalcified sections were mounted in $\mathbf{5}$ per cent sodium sulphate and photographed in polarised light (crossed Nichol prisms).

X-ray diffraction-A Siemen Crystalloflex II diffraction unit with copper $K a$-radiation filtered in $\mathrm{Ni}$ served as radiation source. A Hilger powder camera with 190 millimetre diameter was used to record the diffractograms.

\section{RESULTS}

Histological examination-Bone tissue from osteogenesis imperfecta revealed similar findings in our four cases. Thus, in the long bones, instead of normal compact bone a coarse fibrillar bone of immature type was found. The epiphysial plate was irregular and sometimes rather broad, and the columnar proliferating cartilage was abnormal. For a detailed description of the histological findings in osteogenesis imperfecta the reader is referred to the work of Wilton (1932).

Microradiography-Figure 3 is an enlarged microradiograph of a transverse section of a normal femoral diaphysis from a child who was seven years of age at death and showed no signs of bone disease. The microradiographic picture of normal bone has been described in detail by Amprino and Engström (1952). Different parts of compact bone have a different absorption of $x$-rays, indicating that the bone is not uniformly calcified. Different Haversian systems (osteones) contain a varying amount of mineral salts, systems with the least being the youngest. When the Haversian systems grow older their mineral content progressively increases. The old bone (fragments of old Haversian systems and interstitial lamellae) surrounding the osteones has the highest content of calcium salts. In the normal compact bone a continuous rebuilding is going on. Resorption cavities are formed, involving old bone as well as Haversian systems at different stages of mineralisation. Later, the cavities formed are again filled with bone substance-that is, new osteones are formed.

The microradiographs from all four cases studied showed the same type of deviation from normal bone tissue. In Case 1 transverse sections from the compact bone of the tibia showed a trabecular coarse-fibred bone tissue of immature type. The degree of mineralisation was the same throughout the sections and no Haversian systems were found. Similar preparations from the diaphysis of different long bones from Cases 2 and 3 revealed the same abnormalities as in Case 1. No normal compact bone could be demonstrated and the marrow cavity was partly replaced by trabecular bone tissue. Several fractures of varying age were found. Figure 4 is an enlargement of a microradiograph of a cross-section from the femur of Case 4. No Haversian systems can be seen in this section and there are numerous large resorption cavities. The normal pattern of the tissue is completely disturbed. Figure $\mathbf{b}$ is a highly magnified microradiograph from the same case showing the detailed structure of the spongy bone trabeculae. The osteocytes appear as round or spindle-shaped areas transparent to x-rays. In osteogenesis imperfecta these areas are bigger and more numerous than in normal bone of the same stage of development. Only a few poorly organised Haversian systems could be seen in some sections. As far as can be judged by this method the mineral content is, in most instances, the same in all parts of the bone, the varying degrees of mineralisation of different parts of the skeleton characteristic for normal compact bone being absent. However, in sections from Case 4, some normal Haversian systems were found in the otherwise abnormal bone of the compacta, indicating that a partial normal rebuilding of bone tissue was taking place. In this case we also found numerous large resorption cavities in the abnormal compacta. As can be seen from Figure 4, these cavities were lined in some places with newly formed bone tissue, as indicated by its low degree of mineralisation. Cementing lines separating bone tissue formed at different times could also be detected in these specimens.

Polarised light-Figure 8 shows the regular arrangement of the collagen fibres in a crosssection from normal compact bone. Figure 7 is a photomicrograph in polarised light of the same decalcified section shown in the microradiograph in Figure 5. Instead of concentric 


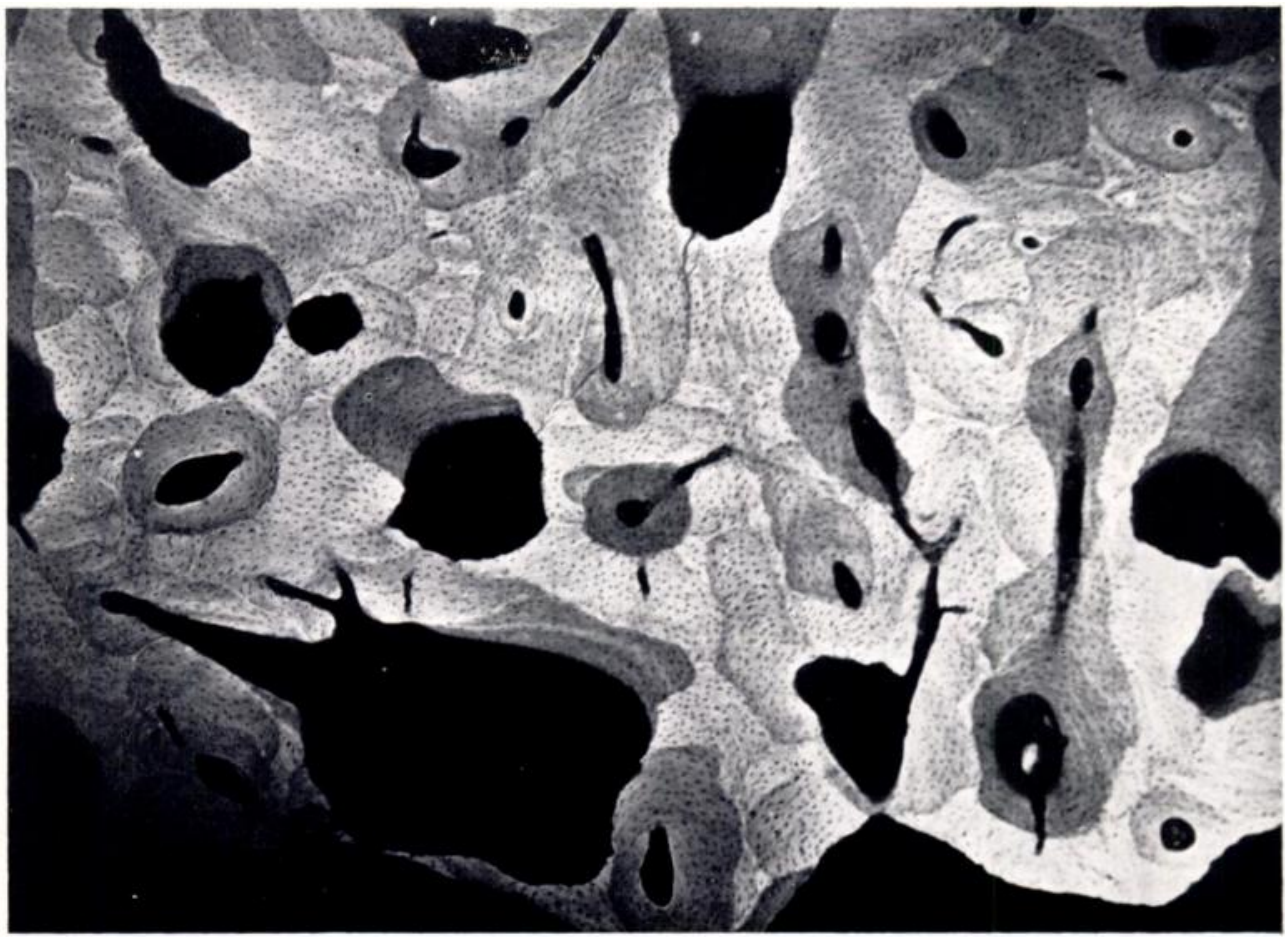

FIG. 3

Microradiograph from ground cross-section of the diaphysis of normal femur from a seven years old child. $(\cdot 50)$.)

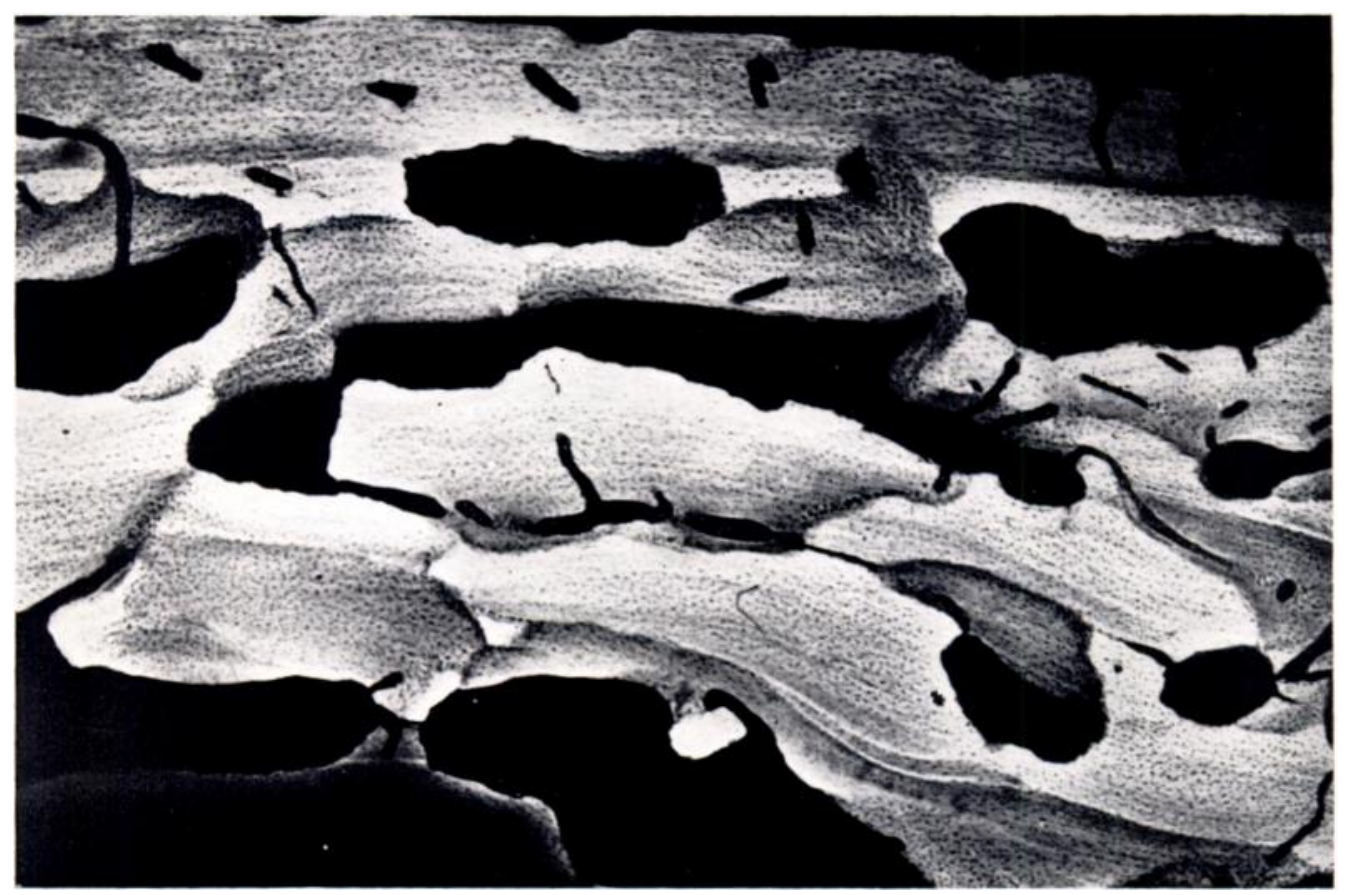

Fig. 4

Microradiograph from ground cross-section of the diaphysis of femur from (ase 4. (. 50). 


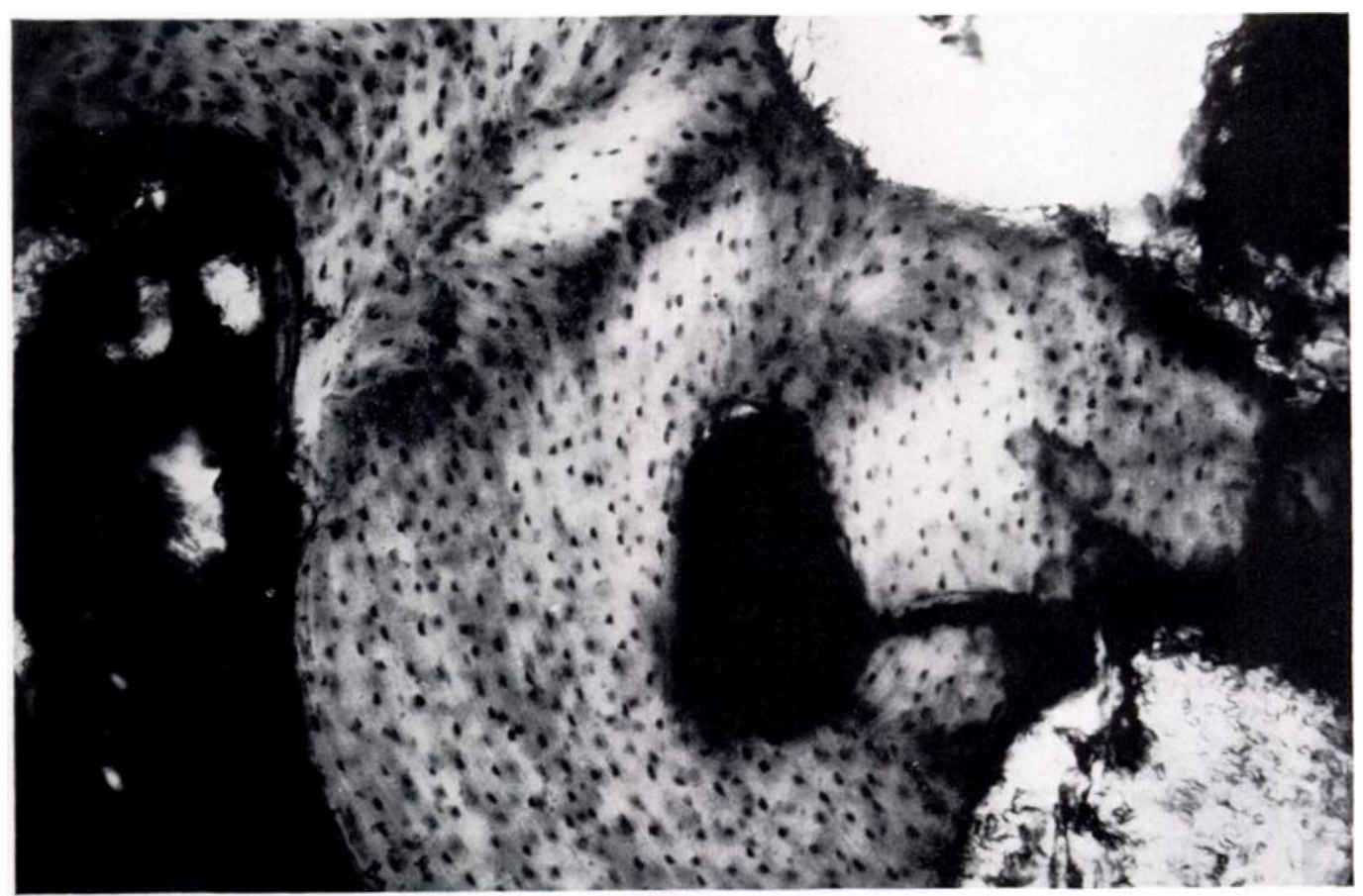

Fig. 5

Case 4-Decalcified ground section, transmitted light. ( $(110$.

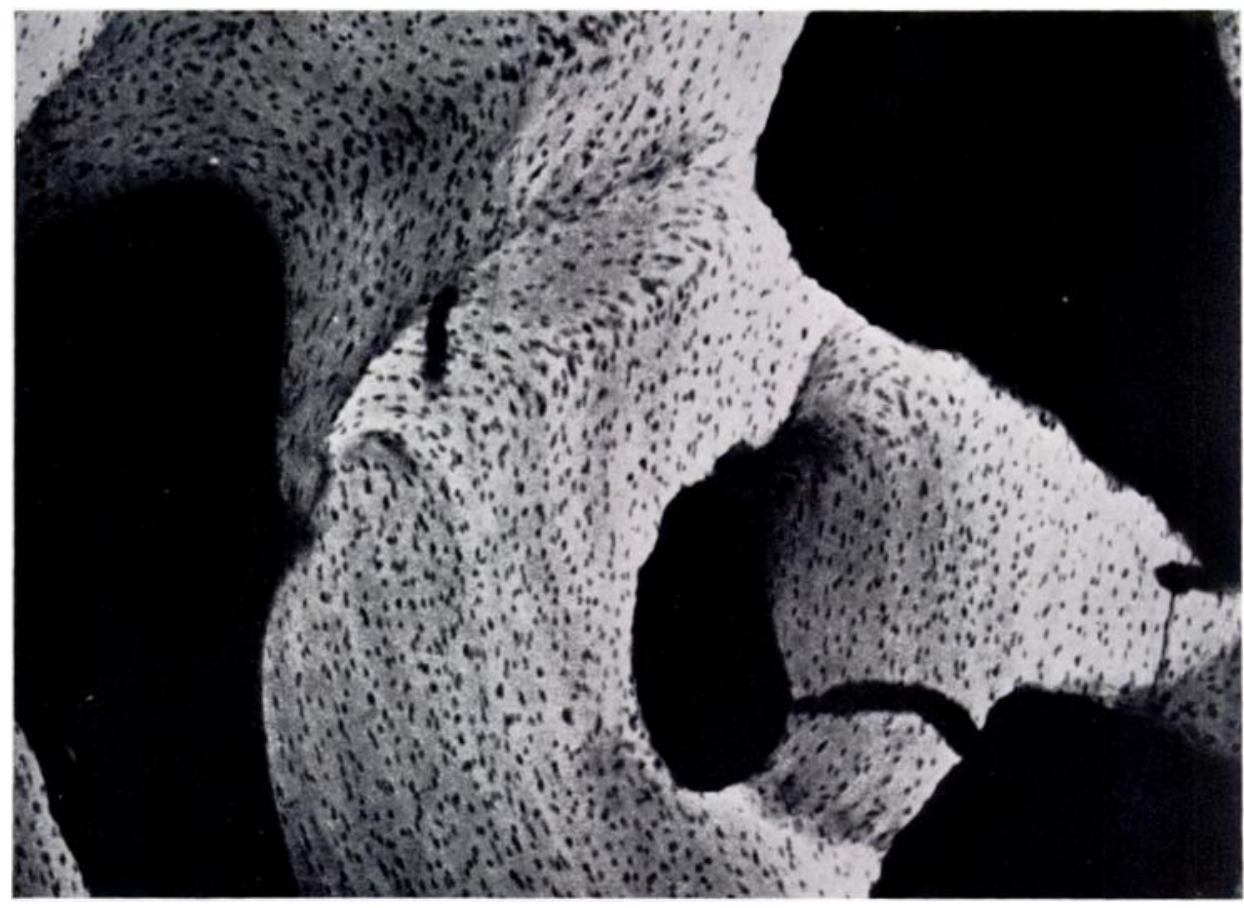

FIG. 6

Case 4-Microradiograph of the same section before decalcification 


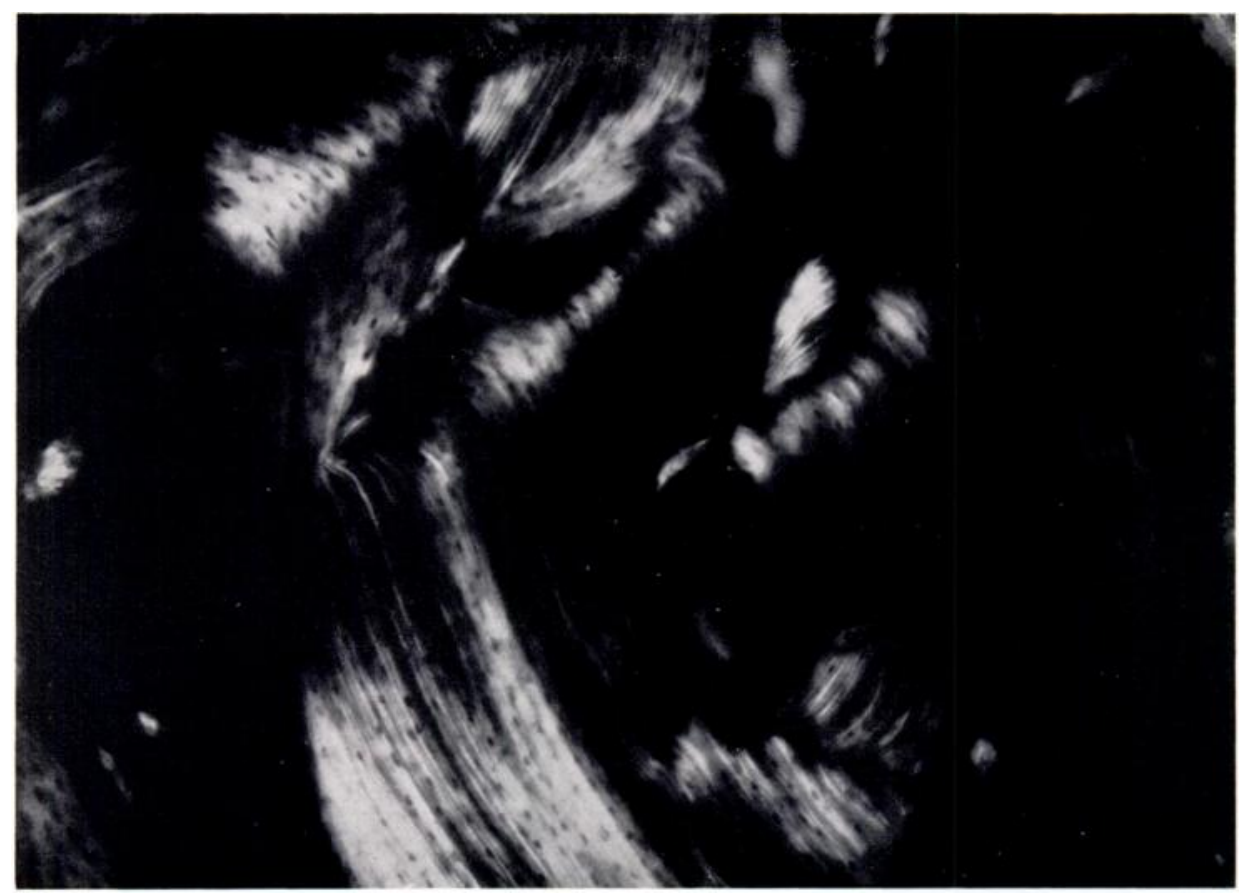

FIG. 7

Case 4-The same decalcified section in polarised light

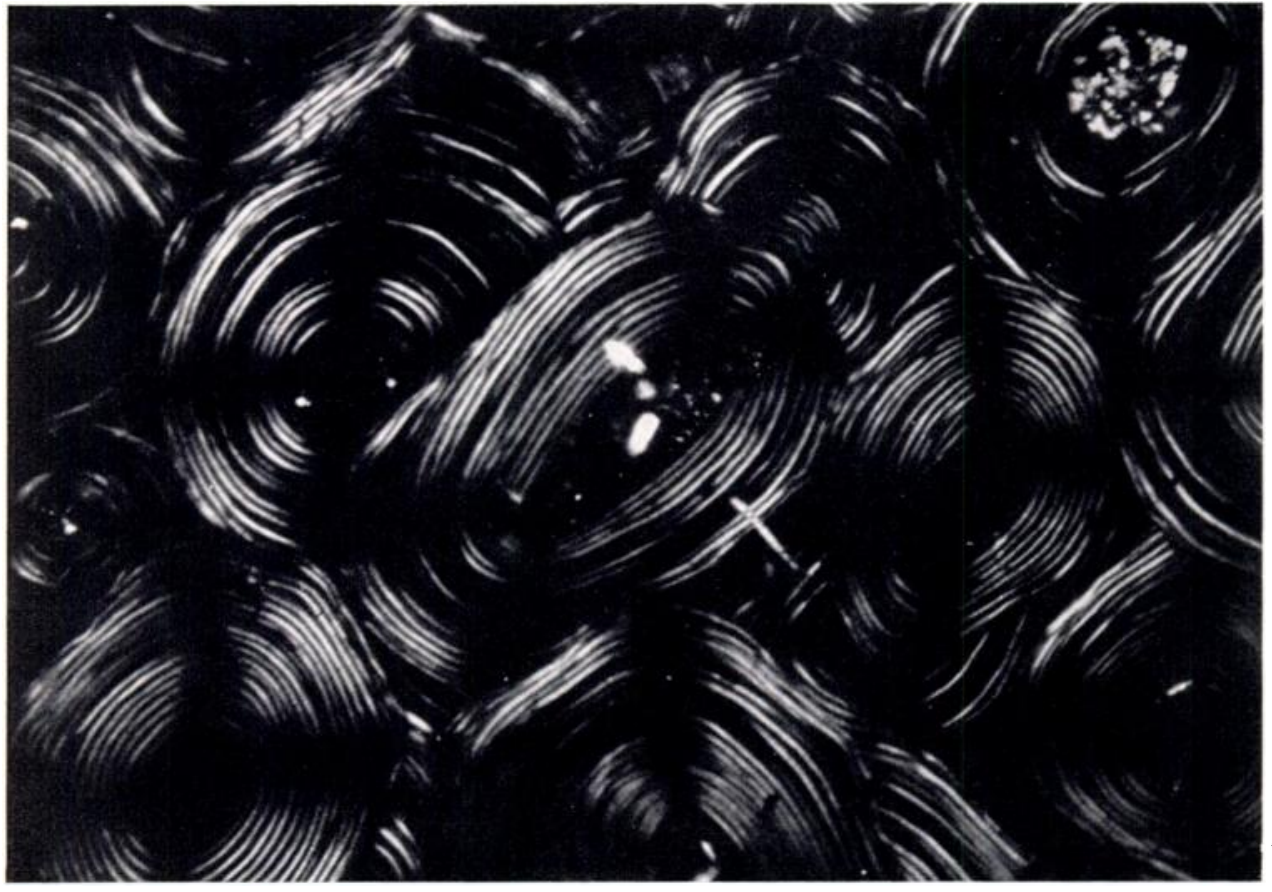

Fig. 8

Decalcified cross-section from normal compact bone of femur, polarised light. $(\times 110$. 
layers of collagen fibres there is a quite irregular arrangement. In some areas there are short broad bundles going in different directions; in others there is no evidence of orientation whatever. A comparison with the microradiograph shows that the ratio between collagen and mineral salts differs widely in different parts of the bone trabeculae.

$\mathbf{X}$-ray diffraction-The $\mathrm{x}$-ray diffraction pattern of bone from osteogenesis imperfecta was found to be identical with that of normal bone. The diffraction lines are rather diffuse, indicating relatively small particles. The diffraction pattern improved on heating in the same way as did the patterns from normal bone. After heating, the pattern still proved to be of the hydroxyapatite type. In longitudinal section of the diseased bone some orientation of the mineral salts could be observed. In normal bone the axis of the apatite crystallites is parallel with the fibre axis of the collagen and so also is the c-axis in the hydroxyapatite unit cell.

\section{DISGUSSION}

This investigation indicates that in osteogenesis imperfecta the compact bone has a quite abnormal distribution of mineral salts and arrangement of organic fibres. The type of mineral distribution and the arrangement of collagen have some features in commom with the newly formed spongy bone of the growth zone. The immature fibrillar bone normally seen in the foetus and the newborn infant resembles in several ways the tissue found in osteogenesis imperfecta. Normally this primary bone tissue is rapidly replaced by secondary bone after birth, but in osteogenesis imperfecta this secondary bone tissue is not found (Fig. 4).

The normal rebuilding of bone tissue and its transformation into compact bone depends on the activity of osteoblasts and osteoclasts. This rebuilding is almost or completely absent in osteogenesis imperfecta, indicating a disturbed function of the osteoblasts and osteoclasts. However, patients who survive longer show that remodelling processes can occur, and these patients grow in size, although often slowly. The rebuilding process which is then seen is of an abnormal type. Resorption of bone tissue occurs, but the new bone formed does not develop into distinct Haversian systems. Instead, an immature lamellar type of bone tissue develops and shows differences in mineralisation of the same kind as are found in normal bone.

The growth in length of the long bones, which is primarily dependent on the growth of epiphysial cartilage, is sometimes stated (Weinmann and Sicher 1947) to be normal in osteogenesis imperfecta. Our findings are not in agreement with this. The histological examination showed an irregular, somewhat broadened, epiphysial plate and proliferation of the cartilage without the typical columnar arrangement. The microradiographs of the epiphysial zone can reveal an irregular zone of calcification which is quite abnormal in appearance. Cases have been described in which the abnormal bone tissue reverts to normal. Different findings in the epiphysial zones might thus perhaps be explained as depending on differences in the stage of development of the disease.

The skeleton in osteogenesis imperfecta is very fragile. Our results seem to indicate that this fragility of the skeleton is dependent not only upon the absence of normal compact bone but on the irregular arrangement of the organic matrix.

It is commonly supposed that the disease is caused by an abnormality of bone formation. The absence or deficiency of some factor responsible for the development of the calcified metaphysial tissue into functionally normal bone may be concerned. In ectopic bone tissue produced by injecting ethyl alcohol intramuscularly in rabbits the distribution of the mineral salts and the arrangement of the collagen fibres resembles that found in osteogenesis imperfecta (Engfeldt and Engström, unpublished), the bone tissue formed in both instances being of an immature type. In ectopic bone there is certainly lack of organ differentiation, and in osteogenesis imperfecta the disturbed development of bone tissue conditioned by a genetic abnormality of the mesenchymal cells also appears to manifest itself in a poor organ differentiation. 
SUMMARY

Results are given of a study of four cases of osteogenesis imperfecta using biophysical methods comprising microradiography, microscopy using polarised light, and x-ray diffraction. Rebuilding of bone tissue was infrequent in the material studied and has been shown to occur in an abnormal manner. The mineralisation of the bone is more uniform than is found in normal bone. The collagen has an abnormal organisation and is sparse. The ultrastructure of bone salts and their orientation are as in normal bone.

\section{REFERENCES}

Albright, F., and Reifenstein, E. C. (1948): The Parathyroid Glands and Metabolic Bone Disease. Baltimore: The Williams and Wilkins Company. London: Baillière, Tindall and Cox.

Amprino, R., and Engström, A. (1952): Studies on X Ray Absorption and Diffraction of Bone Tissue. Acta Anatomica, 15, 1.

Exgfeldt, B., Engström, A., Helander, C. G., Wiltox, A., and Zetterström, R. (1952): Biophyysical Studies on Bone Tissue. 1. Paget's Disease. Acta Pathologica et Microbiologica Scandinavica, 31, 256.

Exgfeldt, B. (1953): Biophysical Studies on Bone Tissue. II. The in Vitro Uptake of Radioactive Phosphate in Normal and Paget Bone. Acta Pathologica et Microbiologica Scandinavica, 32, 529.

F.sgfe!dt, B., Fxgström, A., and Zetrerström, R. (1954): Biophysical Studies on Bone Tissue. III. Osteopetrosis (Marble Bone Disease). Acta Paediatrica, 43, 152.

E.sgström, A., and Wegstedt, L. (1951): Equipment for Microradiography with Soft Roentgen Rays. Acta Radiologica, 35, 345.

Weinmaxx, J. P., and Sicher, H. (1947): Bone and Bones. St Louis: The C. V. Mosby Company.

Wilton, A. (1932): Die Skeletveranderungen bei einem Spatfalle von Osteogenesis imperfecta nebst Erorterung der Entstehungsweise unter Berucksichtigung anderer Skeletkrankheiten. Virchow's Archiv, 283, 778 . 